Artigo

\title{
AVALIAÇÃO DA QUALIDADE POSICIONAL DE DADOS ESPACIAIS GERADOS POR VANT UTILIZANDO FEIÇÕES PONTUAIS E LINEARES PARA APLICAÇÕES CADASTRAIS
}

\author{
Assessment of positional quality in spatial data generated by VANT using point \\ and linear feature for cadastre applications
}

\author{
Francisco de Deus Fonseca Neto ${ }^{1,2}$ \\ Joel Gripp Júnior 1 \\ Mosar Faria Botelho ${ }^{3}$ \\ Afonso de Paula dos Santos ${ }^{1}$ \\ Lécio Alves Nascimento ${ }^{1,4}$ \\ Alessandra Lopes Braga Fonseca ${ }^{1,2}$
}

\begin{abstract}
1Universidade Federal de Viçosa, Viçosa - MG, Brasil, email: jgripp@ufv.br; afonso.santos@ufv.br; lecio.nascimento@ufv.br; alessandra.fonseca@ufv.br;

2Instituto Federal do Espírito Santo (IFES), Vitória - ES, Brasil, email: franciscogeoifes@gmail.com

${ }^{3}$ Instituto Federal Sul de Minas Gerais (IFSULDEMINAS), Inconfidentes - MG, Brasil, email: mosar.botelho@ifsuldeminas.edu.br

${ }^{4}$ Instituto Federal de Educação, Ciência e Tecnologia do Norte de Minas Gerais (IFNMG) - Campus Araçuaí - MG, Brasil, email: lecio.nascimento@ifnmg.edu.br
\end{abstract}

\section{Resumo:}

Atualmente a validação da qualidade das informações cartográficas tem sido um tema cada vez mais evidente e de extrema importância. Com o surgimento da Infraestrutura Nacional de Dados Espaciais (INDE), surgiram diversas especificações técnicas com a finalidade de regulamentar e padronizar os inúmeros processos relacionados à produção cartográfica nacional. Nesse contexto, o objetivo do presente estudo é avaliar a acurácia posicional planimétrica de uma ortofoto gerada a partir de um sensor embarcado em uma plataforma VANT, através da aplicação dos métodos de feições pontuais e lineares, de acordo com o padrão de acurácia posicional brasileiro (Decreto-lei 89.817 aliado à ET-ADGV), considerando como referência um levantamento topográfico executado utilizando a tecnologia GNSS (Global Navigation Satéllite System) e método de posicionamento RTK (Real Time Kinematic). Os resultados alcançados demostram que tanto o método de feição linear (método Buffer Duplo) quanto o método de feição pontual apresentaram resultados similares, obtendo-se segundo o Decreto-lei $\mathrm{n}^{\circ} 89.817 \mathrm{em}$ concordância com a ET-ADGV classificação classe B para a escala 1:1000.

Palavras-chave: VANT; Acurácia Posicional; Feição Linear. 


\begin{abstract}
:
Currently the validation of the quality of cartographic information has been an issue ever more evident and important. With the emergence of the National Spatial Data Infrastructure (INDE) in Brazil, there were several technical specifications in order to regulate and standardize the many processes related to national cartographic production. In this context, the objective of this study is to evaluate the positional planimetric accuracy of orthophoto generated from an embedded sensor on a UAV platform by applying methods of point and linear features, according to the Brazilian standard for positional accuracy (Decree Law 89817 combined with ET-ADGV), considering as a reference survey performed using RTK GNSS positioning technology. The results obtained demonstrate that both linear feature method (Double Buffer method) and the pontual feature method showed similar results, obtaining classification Class B to scale 1: 1,000, according to the Decree Law No. 89,817 / ET-ADGV.
\end{abstract}

Keywords: UAV; Positional Accuracy; Linear Feature.

\title{
1. Introdução
}

Observa-se em dias atuais que o espaço geográfico tem sofrido mudanças significativas, oriundas de fenômenos naturais ou artificiais (entende-se por fenômenos artificiais aqueles que são desenvolvidos sob a ação do homem). Estes processos acontecem, em sua maioria, de forma rápida, não permitindo acompanhamento contínuo, o que acentua a observância sobre a desatualização cartográfica.

Roberto (2013) afirma que o acompanhamento dessas mudanças tem sido há anos realizado por técnicas de Fotogrametria e Sensoriamento Remoto. Utilizando-se dos princípios das técnicas citadas anteriormente, destacam-se atualmente as plataformas dos Veículos Aéreos Não Tripulados (VANTs) que, atuando de forma conjunta com sensores (câmeras não métricas) embarcados, constituem-se como uma alternativa para a atualização cartográfica. Segundo Braz et al. (2015), esses Sistemas Conjuntos (SCs) - integração entre uma plataforma VANT e um sensor - se sobressaem devido a vários fatores, como: à sua resolução espacial, liberdade destinada ao operador para a obtenção de imagens em diferentes momentos, facilidade no planejamento e desenvolvimento de planos de voos, grande possibilidade de se estruturar uma base de dados com imagens multitemporais, possibilitando, assim, agilidade nos procedimentos e, consequentemente uma redução do custo aos usuários.

Nesse contexto, o mercado de geotecnologias vem apresentando os SCs como alternativa tecnológica, em que demonstra sua eficiência quando empregados ao mapeamento de pequenas áreas, proporcionando resolução temporal na ordem de minutos e alta resolução espacial (Eisenbeiss, 2004; Nebiker et al., 2008; Bento, 2008; Pegoraro e Philips, 2011).

Os fatores mencionados, somados ao avanço tecnológico ocorrido nos últimos anos tais como: evolução de hardware e software; maior capacidade de processamento; maior capacidade de armazenamento; processamento em nuvem; materiais de construção; evolução técnica de componentes eletrônicos, como micros controladores, sistemas inerciais e receptores GNSS; dentre outros, justificam a aplicação dos SCs em diversas áreas do conhecimento e com diversas finalidades. 
Dentre as finalidades mencionadas pode-se citar: inspeção do trabalho (Haarbrinck \& Koers, 2006), emergência ambiental (Marenchino, 2009), mapeamento de pastagens (Laliberte et al., 2010), monitoramento de pontes e pavimentos de estradas (Chen, 2011), cartografia (Roig et al., 2013), avaliação de câmera de pequeno formato para uso de aerolevantamento (Ferreira, 2014), para mapeamento tridimensional (Nex \& Remondino, 2014), gerenciamento de colheita (MesasCarrascosa et al., 2015), atualização de cadastro florestal (Braz et al. 2015), dentre outras.

Nesse caso, a necessidade do desenvolvimento de pesquisas relacionadas à utilização dessa tecnologia torna-se evidente, tanto no âmbito da segurança para integração dessa categoria ao espaço aéreo, bem como ao seu uso para a aquisição de dados cartográficos para várias aplicações (Lucieer et al., 2012). Dentre as aplicações que utilizam como ferramenta os produtos cartográficos gerados por SCs, pode-se citar o Cadastro Técnico Multifinalitário (CTM). Isso se justifica pela necessidade de o CTM apresentar uma necessidade de atualização em seus diversos elementos, em especial a sua base cartográfica, atualizada de forma contínua, ou o mais próximo disso. Tal continuidade reflete a importância de se efetuar, não somente um acompanhamento temporal de elementos importantes já cadastrados, mas também proceder ao cadastramento de novos elementos. Diversas são as áreas de abrangência do CTM, tais como: saneamento básico, cadastro de ruas e vias de acesso, mapeamento de redes elétricas, determinação de limites de imóveis, definições de parcelas, regularização fundiária etc.

Atualmente, o Ministério do Meio Ambiente (MMA) tem se apoiado no CTM como ferramenta para o desenvolvimento de políticas públicas e fiscais, visando principalmente, à preservação e manutenção ambiental em localidades rurais, instituídas pelo Cadastro Ambiental Rural (CAR). Um dos instrumentos legais que norteiam o CAR é instituído pela Lei $\mathrm{n}^{\circ} 12.651$, de 25 de Maio de 2012 (novo código florestal), em que estabelece normas gerais sobre a proteção da vegetação, áreas de Preservação Permanente e as áreas de Reserva Legal; a exploração florestal, o suprimento de matéria-prima florestal, o controle da origem dos produtos florestais e o controle e prevenção dos incêndios florestais, e prevê instrumentos econômicos e financeiros para o alcance de seus objetivos.

No entanto, devido á importância atrelada aos itens acima citados, a Lei n ${ }^{\circ} 12.651$ não apresenta critérios que possam direcionar a avaliação da qualidade posicional dos dados utilizados, ou seja, não há o estabelecimento de tolerâncias posicionais aplicáveis aos dados espaciais utilizados para a realização do CAR. Nesse contexto, propõe-se como uma forma de melhoria para tal procedimento a avaliação e validação da qualidade posicional dos dados espaciais que são utilizados para esse fim.

Atualmente, a validação da qualidade das informações cartográficas tem sido um tema cada vez mais evidente e de extrema importância. Com o surgimento da Infraestrutura Nacional de Dados Espaciais (INDE) em outubro de 2007, proposta pelo Decreto Presidencial no 6.666 de 27 de Novembro de 2008, surgiram diversas especificações técnicas com a finalidade de regulamentar e padronizar os inúmeros processos relacionados à produção cartográfica nacional.

Dessa forma, Galo e Camargo (1994), Karnaukhova e Loch (2001), Goodchild (2010), Lunardi et al. (2012) e Santos et al. (2015) entendem que é de extrema importância a análise da qualidade posicional, uma vez que a criação e disseminação de produtos cartográficos se tornou rápida e, na maioria dos casos, tem a qualidade cartográfica negligenciada.

Leis, Normas e padrões foram desenvolvidos, em diversos países, com o intuito de introduzir metodologias para a análise de qualidade posicional de produtos cartográficos, avaliando assim a acurácia posicional. Uma das características principais destes padrões consiste na comparação entre pontos de checagem homólogos pertencentes às bases cartográficas distintas. No Brasil, a avaliação da qualidade posicional que se utiliza dessa metodologia é regimentada pelo Decreto- 
lei $\mathrm{n}^{\circ}$ 89.817, de 20 de junho de 1984 e, que pode ser complementada pela ET-ADGV (Especificação Técnica de Aquisição de Dados Geoespaciais Vetoriais) elaborada pela DSG (Divisão do Serviço Geográfico do Exército Brasileiro).

Nesse contexto, Castejon et al. (2013) afirma que a validação de uma imagem registrada pode ser realizada a partir de referenciais por amostras pontuais, por linhas e até por sub-imagens.

Portanto, a investigação através de métodos de avaliação da acurácia posicional que utiliza feições lineares, tem sido de grande relevância em diversos estudos relacionados ao Sistema de Informações Geográficas. Sendo assim, a comunidade científica destina um grande esforço, já há algumas décadas para a compreensão e desenvolvimento de diferentes técnicas de avaliação (Tong et al., 2015).

De acordo com Santos et al. (2015), o uso de feições lineares como método de avaliação da acurácia posicional busca comparar a linha teste em relação à linha tida como referência. Por fim são avaliados alguns aspectos, tais como: quantidade de vértices, angularidade, razão entre os comprimentos, índices de sobreposição e interseções, etc.

Baseado na contextualização supracitada, este trabalho tem como objetivo avaliar a acurácia posicional planimétrica de um produto gerado utilizando o aerolevantamento, efetuado por um SC, através da aplicação dos métodos de feições pontuais e lineares, de acordo com o padrão de acurácia posicional brasileiro (Decreto-lei 89.817 aliado à ET-ADGV), considerando como referência um levantamento topográfico executado utilizando a tecnologia GNSS (Global Navigation Satéllite System) e método de posicionamento RTK (Real Time Kinematic).

Como os sensores embarcados às plataformas VANTs tem sido uma ferramenta cada vez mais utilizada para aquisição de dados espaciais com a finalidade Cadastral Ambiental Rural por diversas instituições, justifica-se esse trabalho pela necessidade de se efetuar a avaliação e validação da qualidade posicional de dados espaciais gerados por SCs (ortofotos), destinados a aplicações no CAR, utilizando metodologias consistentes, como as (ou algumas) apresentadas por Santos et al. (2015). A não exigência de critérios posicionais rigorosos impostos pela legislação que rege o CAR (Lei $n^{\circ}$ 12.651) corrobora para a deterioração de informações relevantes ao desenvolvimento sustentável do país. Nesse contexto, esse estudo pode ser utilizado, de forma a compor, nortear ou auxiliar demais pesquisas, com o foco no desenvolvimento de critérios que amparem a qualidade de dados espaciais destinados ao CAR.

\section{Padrão de acurácia posicional brasileiro}

Santos et al. (2015) enfatiza que existem vários métodos de avaliação da acurácia posicional que utilizam feições pontuais, sendo que todos eles são similares. A semelhança entre os métodos se dá devido ao fato de realizarem a comparação entre a amostra de pontos de checagem, obtida em campo ou em algum dado espacial mais acurado, com a amostra de pontos homólogos no dado espacial em avaliação. A partir dos resultados gerados dessa comparação, diversas formulações e testes estatísticos são aplicados de acordo com a norma de acurácia posicional utilizada.

No Brasil, a norma oficial utilizada para a avaliação da acurácia posicional é estabelecida pelo Decreto-lei $n^{\circ}$ 89.817, de 20 de junho de 1984. De acordo com Brasil (1984), DSG (2011), DSG (2015), esse decreto estabelece critérios para classificação de cartas utilizando como parâmetros um indicador estatístico da qualidade posicional, denominado de Padrão de Exatidão 
Cartográfica (PEC). Tal decreto, à época de sua publicação, apresentou como objetivo principal assegurar a qualidade posicional cartográfica de produtos analógicos, estabelecendo três classes de produtos cartográficos (A, B e C), de acordo com o indicador estatístico PEC do produto avaliado.

Devido à evolução tecnológica, a popularização de equipamentos que utilizam dados e informações geoespaciais e as demandas dos usuários, percebeu-se a necessidade de estabelecer novos padrões de qualidade para os produtos cartográficos (DSG, 2015). De forma a atender tal necessidade, em junho de 2011, foi elaborada pela Diretoria de Serviço Geográfico do Exército Brasileiro (DSG) em conformidade com a Infraestrutura Nacional de Dados Espaciais (INDE), a especificação técnica que regula e padroniza a aquisição da geometria dos dados geoespaciais vetoriais e atributos correlacionados, intitulada ET - ADGV (DSG, 2011). Tal especificação técnica, em um de seus itens, apresenta os procedimentos referentes à aplicação do Decreto-lei $\mathrm{n}^{\circ}$. 89.817, bem como a criação de uma classe mais restritiva, destinadas para produtos cartográficos digitais (PCD) (SANTOS et al., 2015). Os produtos digitais foram classificados em 4 (quatro) classes (A, B, C e D), sendo que as classes B, C e D correspondem, nessa ordem, as classes A, B, C do Decreto no 89.817, de 20 de junho de 1984 (DSG, 2015).

Santos et al. (2015) afirma que no Decreto-lei 89.817 está implícito que os dados de discrepâncias posicionais sigam a distribuição normal. Portanto, para se utilizar o padrão de acurácia posicional seguindo tal Decreto-lei e, consequentemente, a ET-ADGV, deve-se inicialmente atestar a normalidade da amostra de discrepâncias posicionais. Existem diversos testes que podem ser utilizados para a verificação da normalidade, dentre eles pode-se citar: Shapiro-Wilk, Komolgorov-Smirnov, Anderson-Darling, Qui-Quadrado, entre outros.

Segundo BRASIL (1984), Sztutman (2014), DSG (2015) e Santos et al. (2015) existem 2 (dois) critérios que devem ser atendidos para que um produto cartográfico seja classificado quanto ao Decreto-lei 89.817, a saber: (i) $90 \%$ dos pontos testados devem apresentar valores de discrepâncias iguais ou inferiores ao valor do PEC-PCD em relação à escala e a classe testada e; (ii) o RMS (root mean square) das discrepâncias deve ser igual ou inferior à tolerância EP definido pela norma, apresentados na Tabela 1.

Tabela 1: Valores de tolerância para avaliação da acurácia posicional planimétrica segundo o Decreto-lei no 89.817 em concordância com a ET-ADGV.

\begin{tabular}{l|l|l|l|l|l}
\hline \multicolumn{1}{c|}{ Classe } & \multicolumn{1}{c|}{ Classe } & \multicolumn{2}{c}{ Planimetria } & \multicolumn{2}{c}{ Escala 1:1000 } \\
\hline \multicolumn{1}{c|}{ PEC } & PEC-PCD & PEC (mm) & EP(mm) & PEC(m) & EP*(m) \\
\hline- & A & $0,28^{*} D$ & $0,17^{*} D$ & 0,28 & 0,17 \\
\hline A & B & $0,50^{*} D$ & $0,30^{*} D$ & 0,50 & 0,30 \\
\hline B & C & $0,80^{*} D$ & $0,50^{*} D$ & 0,80 & 0,50 \\
\hline C & D & $1,00^{*} D$ & $0,60^{*} D$ & 1,00 & 0,60 \\
\hline
\end{tabular}

*EP é uma tolerância chamada erro padrão de acordo com o Decreto-lei no $89.817 ; D$ representa o denominador da escala utilizada.

A Equação 1 descreve o modelo matemático utilizado para a determinação da discrepância planimétrica, sendo a resultante posicional entre as coordenadas de campo ou referência $\left(\mathrm{X}_{\text {ref }}\right.$, $\left.\mathrm{Y}_{\text {ref }}\right)$ com as coordenadas do dado espacial em teste $\left(\mathrm{X}_{t e s}, \mathrm{Y}_{\text {tes }}\right)$. Consequentemente, o modelo matemático para o cálculo do RMS das discrepâncias pode ser observado na Equação 2. 


$$
\begin{gathered}
\text { Disc }_{p}=\sqrt{\left(X_{\text {tes }}-X_{\text {ref }}\right)^{2}+\left(Y_{\text {tes }}-Y_{\text {ref }}\right)^{2}} \\
R M S_{\text {Disc }}=\sqrt{\frac{\sum_{i=1}^{n}\left(\text { Disc }_{p_{i}}\right)^{2}}{n-1}}
\end{gathered}
$$

Segundo Santos (2010), quando se aplica o controle de qualidade de dados espaciais, é de fundamental importância a análise de tendências (efeitos sistemáticos). Tal análise se justifica, pois, ao se utilizar um dado tendencioso a integração entre dados fica impossibilitada, podendo gerar análises inconsistentes, influenciando negativamente os processos decisórios, gerando produtos que não condizem com a realidade de campo. Nesse contexto, é comum que se efetue testes estatísticos para a verificação de tendências em dados espaciais. Santos (2010), Lima (2012), Sztutman (2014), afirmam que, na análise de tendências em dados espaciais, utilizam-se o teste $t$ de Student na amostra de discrepâncias posicionais $(d)$ de modo a verificar se a média das discrepâncias posicionais é estatisticamente igual à zero, inferindo, assim, se o produto avaliado apresenta tendência ou não à um determinado nível de confiança. Vale ressaltar que o teste $t$ de Student (teste de hipótese), exige que a amostra siga distribuição normal.

Nesse caso, como ressalta Lima (2012), a análise de tendência é de extrema importância, pois, existindo erro sistemático, ou seja, tendência, esta pode ser eliminada com uma simples translação na direção em que se constata tal ocorrência, o que corresponde a subtrair o valor da média de cada valor de discrepância.

\section{Método do Buffer Duplo para avaliação da acurácia posicional utilizando feições lineares}

Dentre os diversos métodos de controle de qualidade cartográfica podemos citar os que se fundamentam sobre feições lineares. Como mencionado por Santos et al. (2015), tais métodos não são frequentemente divulgados e nem aplicados em estudos aprofundados no Brasil. Esses métodos, em sua maioria, apresentam como finalidade a avaliação dos resultados gerados no processo, ou método, de generalização cartográfica.

Os principais métodos que adotam feições lineares podem ser subdivididos em 3 (três) categorias: 1) os de faixa de incerteza que utilizam uma abordagem determinística; 2) os de faixa de incerteza que utilizam uma abordagem estocástica e; 3) os de métodos determinísticos que realizam análises geométricas. Dentre os métodos de tipo 1, pode-se citar os da Banda Épsilon ou Método das Áreas, Buffer Simples e Buffer Duplo. Portanto, optou-se por utilizar para este trabalho o Buffer Duplo, justificável pela apresentação dos melhores resultados em estudos desenvolvidos por Santos et al. (2015).

Tveite e Langaas (1999) propuseram o método do Buffer Duplo, chamado pelos autores de Buffer Overlay Statistics. Este procedimento é efetuado aplicando-se o modelo da faixa de incerteza nas duas linhas utilizadas (linha de referência e linha de teste), ou seja, aplica-se um buffer em ambas as linhas, e em seguida realiza-se uma interseção entre os polígonos resultantes dos buffers obtendo-se assim uma medida de discrepância média entre as feições lineares. A 
partir dos resultados obtidos na etapa supracitada, é possível avaliar posicionalmente a acurácia do dado espacial em teste.

A Equação 3 descreve o modelo matemático utilizado para o cálculo da discrepância $(d m)$, que é obtida multiplicando-se o valor de pi $(\pi)$ pela largura do buffer $(x)$ e pelo somatório da área do buffer da linha de referência que não faz interseção com o buffer da linha de teste ( $A_{\text {Fora }}$ ), dividido pelo valor da área formada pelo buffer da linha teste $\left(A B_{L T}\right)$.

$$
d m_{i}=\pi \cdot x \cdot \frac{\left(\sum A_{F o r a}\right)_{i}}{A B_{L T}}
$$

O método do $B$ uffer duplo pode ser observado na Figura 1.

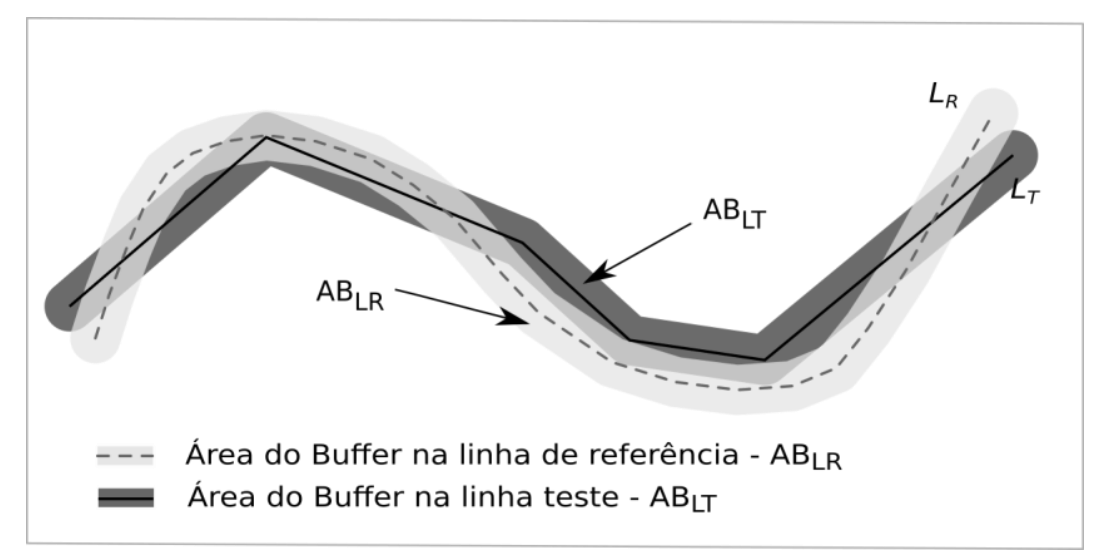

Figura 1: Metodologia do buffer duplo. Fonte: Santos et al. (2015).

Apesar do Decreto-lei não definir o uso de métodos de feições lineares, Santos et al. (2015) sugere a aplicação do método do Buffer Duplo utilizando as tolerâncias do padrão Decreto-lei 89.817/ET-ADGV. Esta aplicação pode ser efetuada seguindo as seguintes etapas:

1. Selecionar uma amostra de $n$ linhas homólogas de teste ( $\left.L_{\text {Test }}\right)$ e de referência $\left(L_{R e f}\right)$;

2. Aplicar um buffer de tamanho $x$ em cada linha $i$ da amostra de linhas homólogas de teste e referência. Para o emprego do Decreto-lei $n^{\circ}$ 89.817, utiliza-se como tamanho do buffer o valor do PEC para a escala e a classe utilizada no processo de avaliação;

3. Calcular a área $A B_{L T}$ gerada pela operação de buffer em cada linha de teste;

4. Fazer uma sobreposição entre os polígonos gerados pelos buffers da linha teste e da linha de referência e calcular o valor de $A_{\text {Fora }}$, referente a área do polígono de referência que não faz interseção ao polígono teste $\left(A B_{L R}-A B_{L T}\right)$;

5. Calcular a discrepância média $(d m)$, para cada linha teste $i$ Equação 3;

6. Para análise do Decreto-lei $\mathrm{n}^{\circ}$ 89.817, sugere-se verificar a independência e normalidade e, se constatada, faz-se a análise se $90 \%$ das linhas testadas apresentam discrepância média $(d m)$ menor ou igual ao valor do PEC (da classe e escala utilizados para gerar o buffer $x$ ), e ainda, o RMS das discrepâncias dm ser menor ou igual ao valor do EP (idem ao PEC). Se as duas condições forem aceitas, classificase o dado espacial de acordo com a classe e escala trabalhada. 


\section{Experimento e Resultados}

\subsection{Sistemas Conjuntos}

Para a realização desse experimento foi utilizado um hexacóptero, modelo F550, cujas características relevantes a esse equipamento são: asa rotativa, envergadura de $80 \mathrm{~cm}$, alimentação a bateria, autonomia de voo de 12 minutos e capacidade de carga $2,8 \mathrm{~kg}$. É composto por: uma plataforma aérea dotada de seis hélices e rotores, um receptor GNSS (Global Navigation Satellite System) para posicionamento absoluto via código (navegação) e um sistema inercial.

O sistema de controle de voo é realizado por um rádio, modelo Futaba T10J, composto por um transmissor que se comunica com um receptor embarcado no hexacóptero. O procedimento de controle de voo é visual e externo a aeronave, com uma visão aérea direta. Isso significa que todo o processo é manipulado via rádio controle e executado pelo piloto de forma visual e, quando possível, será manipulado utilizando a estação base (quando estiver fora do campo de visão).

A câmera (sensor) utilizada para aquisição das imagens é uma Go Pro, modelo Black Edition HERO 3+, programada para adquirir imagens em intervalos de tempo pré-definidos (a cada dois segundos para o caso do estudo em questão). De forma a garantir a estabilidade e rotação da câmera, utilizou-se um suporte Gimbal, modelo Tarot 2D. Esse suporte permite o movimento da câmera de $0^{\circ}$ a $-90^{\circ}$ para a tomada da foto em vista panorâmica ou a nadir.

Neste trabalho, a partir de agora, quando mencionado o termo VANT, refere-se à incorporação de todos os itens anteriormente descritos (hexacóptero, câmera, gimbal etc.), em um único equipamento. O monitoramento e controle do voo fotogramétrico são efetuados a partir de um sistema de comunicação que envia as informações de todos os componentes a bordo para uma estação de recepção localizada em solo. Sua capacidade de programação de voo sugere planejamentos de rota que podem ser executados de forma manual ou automática.

Com o VANT montado, deu-se início ao planejamento do voo e coleta das imagens. O voo foi planejado para recobrir toda a área, a uma altitude de 80m em relação a base, com GSD (Ground Sample Distance - elemento de resolução ou tamanho do pixel no terreno) médio de $4,133 \mathrm{~cm} \mathrm{e}$ sobreposição de $70 \%$. Após a coleta das imagens, efetuou-se o processamento dos dados. Tal processamento foi efetuado utilizando recursos do software Agisoft Photoscan, desenvolvidos especificamente para reconstrução visual tridimensional (3D), porém adaptado para processamento de conjuntos de imagens e dados de levantamentos aéreos de veículos não tripulados. Assim, gerou-se a ortofoto utilizando o Modelo Digital de Superfície (MDS) e 35 pontos de controle distribuídos na área.

\subsection{Avaliação da Acurácia Posicional}


De posse da ortofoto deu-se início aos procedimentos para a avaliação de sua acurácia posicional planimétrica. Foram coletadas em campo 11 feições bem definidas tendo como valor em termo de comprimento total de $282,73 \mathrm{~m}$ e 35 pontos de checagem, conforme pode ser visto nas Figuras 2 e 3. Como o Decreto-lei 89.817-84 / ET-ADGV não define a quantidade de pontos a ser utilizada em uma avaliação da acurácia posicional, utilizou-se a norma americana NSSDA (National Standard for Spatial Data Accuracy) que indica que um mínimo de 20 pontos deve ser utilizado no processo de avaliação, como pode ser observado em FGDC (1998). Alguns passos importantes para obtenção de resultados consistentes durante a coletas dos pontos foram observados bem como: escolha da área, evitar locais com obstrução dos sinais dos satélites pela arborização e/ou edificações; observância do relevo, de modo que os pontos fossem distribuídos pelas baixas, médias e altas altitudes; escolher pontos e trechos de calçadas bem distribuídos espacialmente. Foram utilizados no levantamento de Campo, receptores GNSS de dupla frequência no método de posicionamento RTK (Real Time Kinematic), tanto para a coleta dos pontos quanto para a coleta das feições lineares. Os pontos e as feições levantadas apresentaram uma precisão posicional planimétrica entre 0,5 e $1,1 \mathrm{~cm}$, respectivamente.

Em seguida, foi realizado o processo de vetorização das linhas correspondentes às feições coletadas e as coordenadas dos pontos homólogos na ortoimagem, sendo que todos os processos foram realizados no software ArcGIS10.2. Com as discrepâncias posicionais planimétricas calculadas (feições pontuais) e as discrepâncias médias entre as feições lineares foi possível aplicar os métodos descritos nas seções 2 e 3 para avaliação da acurácia posicional planimétrica da ortofoto gerada.

\subsection{Resultados}

De posse das amostras de discrepâncias, obtidas pelos métodos de feições lineares e por pontos, foram verificadas a normalidade dos dados aplicando-se o teste de Shapiro-Wilk. Utilizou-se o software R (R Core Team, 2014) para a aplicação de tais testes estatísticos, sendo os dados normais ao nível de confiança de $95 \%$. 


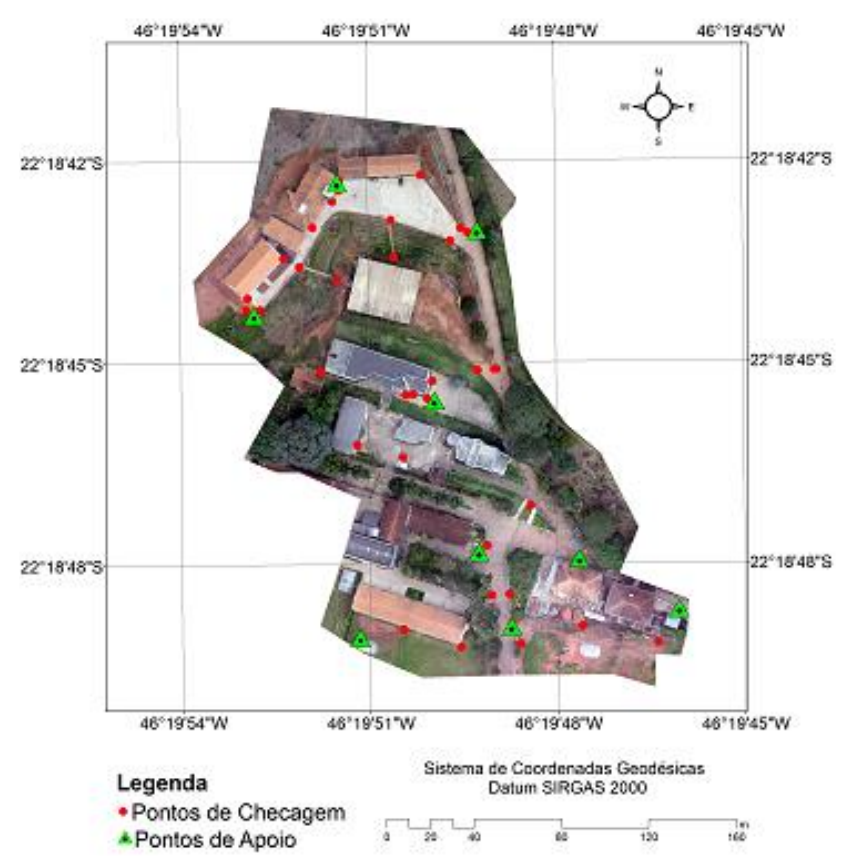

Figura 2: Pontos utilizados no processo de avaliação da acurácia posicional da ortofoto do VANT.

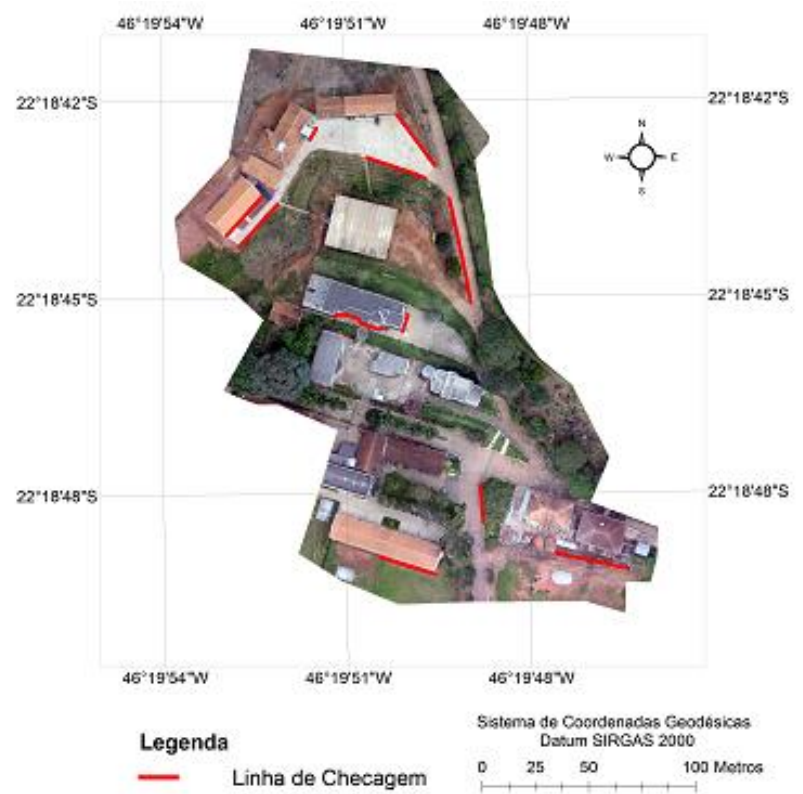

Figura 3: Feições lineares aplicadas ao processo de avaliação da acurácia posicional da ortofoto do VANT.

Constatada a normalidade da amostra de discrepâncias, fez-se a avaliação da acurácia posicional da ortoimagem do VANT utilizando os valores de PEC-PCD e EP para a escala 1:1000, conforme apresentada na Tabela 1. A utilização da referida escala é justificada, por ser utilizada em diversos projetos com finalidades cadastrais. Nesse caso, considerar-se-á como referência 
para a determinação dos parâmetros de qualidade posicional (atrelados à escala utilizada) que tornem as propostas apresentadas nesse trabalho coerentes e relevantes. A adoção de tal escala se dá, também por refletir, de forma satisfatória, o conteúdo informativo do produto cartográfico adotado, de forma que permita a verificação do atendimento ao seu propósito (CAR, CTM ou levantamentos gerais).

Os resultados gerados a partir da aplicação dos métodos de feição linear e do tradicional de pontos são apresentados nas Figuras 4 e 5, onde se possibilita a observação dos valores de: discrepâncias posicionais planimétricas, discrepância média, RMS, valores máximos e mínimos das discrepâncias posicionais observadas na ortofoto, obtida a partir de câmeras de pequeno formato (não métricas) transportadas por um veículo aéreo não tripulado VANT.

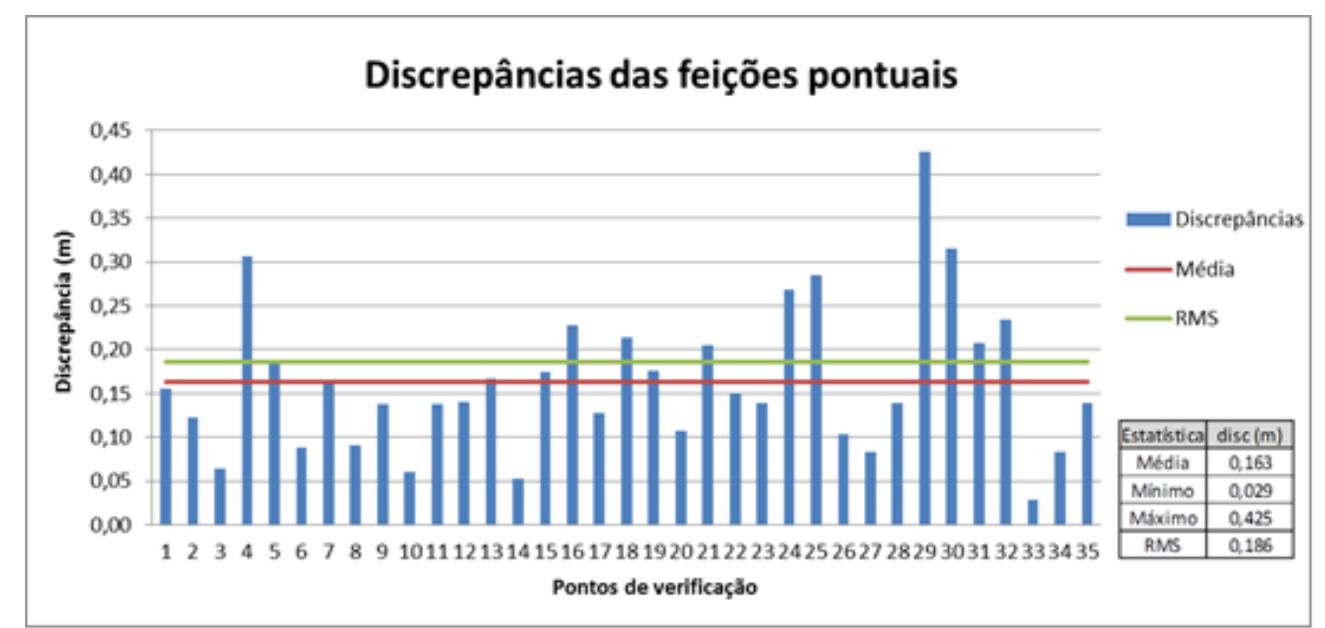

Figura 4: Discrepância posicional planimétrica obtido através do método de Pontos utilizado no processo de avaliação da acurácia posicional.

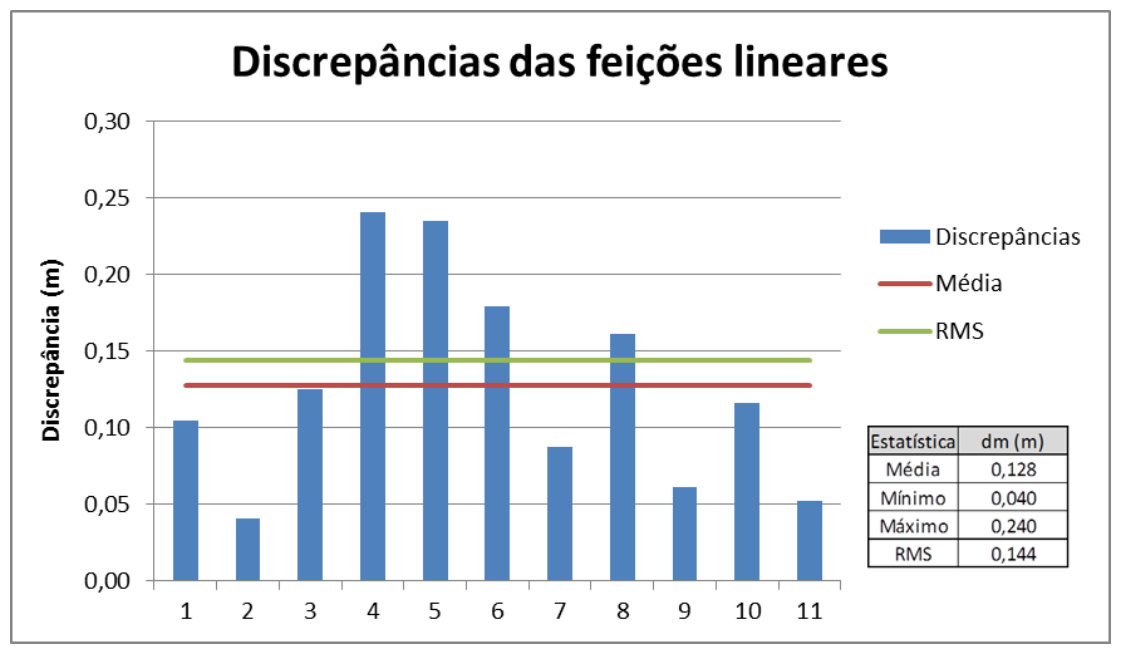

Figura 5: Discrepância posicional planimétrica obtido através do método de feições lineares (Buffer Duplo) utilizado no processo de avaliação da acurácia posicional.

Nos métodos utilizados para avaliação da qualidade posicional, utilizando feições pontuais e lineares, as amostras de discrepâncias apresentaram normalidade. Utilizou-se o teste de Shapiro- 
Wilk, verificando-se um valor de probabilidade significativo a 5\% para todas as amostras analisadas.

O método tradicional (feições pontuais) apresentou valor máximo de discrepância de $0,425 \mathrm{~m}$. Comparando esse valor com o máximo obtido pelo método de feições lineares, de $0,240 \mathrm{~m}$, constata-se que o Buffer Duplo apresentou menor valor. Isso se deve ao fato de que, no método de feições lineares é obtida uma discrepância média, o que justifica maior valor "máximo" de discrepância para o método de feições pontuais. Em contrapartida, quando considerados os valores mínimos, observa-se que o método tradicional mostrou um valor de $0,029 \mathrm{~m}$, bem similar com o método do Buffer Duplo que apresentou um valor de $0,040 \mathrm{~m}$.

Observou-se que a média e o RMS de ambos os métodos de avaliação foram similares. O método tradicional por pontos apresentou valores de, respectivamente, $0,163 \mathrm{~m}$ e $0,186 \mathrm{~m}$, enquanto o método de feições lineares obteve valores de $0,128 \mathrm{~m}$ e $0,144 \mathrm{~m}$.

Ao testar os dois métodos para a Classe A (PEC-PCD) na escala 1:1000 não foi obtido classificação quanto ao Decreto-lei 89.817 / ET-ADGV. Assim, testou-se as discrepâncias posicionais pontuais para a Classe B. No método de feição linear (Buffer Duplo) foi gerada um novo conjunto de discrepâncias médias utilizando como tamanho do buffer a tolerância do PECPCD para a classe B na escala 1:1000. Deste modo, ambos os métodos atenderam às condições do Decreto-lei 89.817 / ET-ADGV, enquadrando-se na Classe B para a escala 1:1000, como se pode observar na Tabela 2.

Tabela 2: Classificação de acordo com o decreto Lei no 89.817VET-ADGV para escala 1:1000 da ortofoto analisada.

\begin{tabular}{l|c|c|c|l|l|l|l}
\hline Método & $\mathbf{n}^{\circ}$ & $\begin{array}{c}\text { Média } \\
(\mathbf{m})\end{array}$ & $\begin{array}{c}\text { RMS } \\
(\mathbf{m})\end{array}$ & $\mathbf{\%}(\mathbf{d i})<$ PEC-PCD & RMS < EP & Tendência & Classificação \\
\hline $\begin{array}{l}\text { Feição } \\
\text { Pontual }\end{array}$ & 35 & 0,163 & 0,186 & $100 \%$ & sim & não & Classe B 1:1000 \\
\hline $\begin{array}{l}\text { Feição } \\
\text { Linear }\end{array}$ & 11 & 0,128 & 0,144 & $100 \%$ & sim & não & Classe B 1:1000 \\
\hline
\end{tabular}

Ao realizar a análise de tendências, verificou-se que tanto as discrepâncias posicionais obtidas dos métodos de feições pontuais e lineares não apresentaram tendências. O teste t de Student foi aplicado ao nível de confiança de $90 \%$. Sendo assim, a ortofoto gerada a partir de imagens obtidas por sensores acoplados à plataforma VANT é acurada posicionalmente para a escala de 1:1000, classe B (Decreto 89.817/ET-ADGV), apresentando discrepâncias médias menores que $20 \mathrm{~cm}$. Tal resultado é satisfatório para a cartografia cadastral, podendo a ortofoto em questão constituir uma ferramenta cartográfica relevante para diversas aplicações, como o Cadastro Técnico Multifinalitário (CTM), o Cadastro Ambiental Rural (CAR), Georreferenciamento de Imóveis Rurais, Cadastro para liberação de crédito rural das instituições financeiras etc.

Segundo Loch (2006) o Cadastro Urbano no Brasil utiliza cartas com escalas que variam entre 1:1000 e 1:2000. Nesse contexto, o ideal seria que os sistemas de gestão cadastral tivessem seus mapas numa escala 1:1000, o que permitiria sua ligação e confrontação com Sistemas de Informações Geográficas (SIGs) para diversas análises de dados. Portanto, os resultados alcançados foram acurados para a escala 1:1000, apresentando assim uma importante contribuição para o planejamento urbano em geral.

Nesse caso, a aplicação direta dos dados avaliados pode ser direcionada, por exemplo, ao cadastro de parcelas nas escalas 1:1000 (demarcação de postes, telefonia etc) e 1:2000 
(desapropriações, aumento nas largura das vias etc). Nota-se, portanto, um aumento na capacidade de identificação e análise dos padrões atuais de uso do solo, da topografia, das mudanças econômicas, da evolução demográfica. Tais aplicações proporcionam também a segurança da propriedade, uma vez que traz transparência aos direitos reais, já que as características geométricas do imóvel (limites) são passiveis de verificação.

Considerando o georreferenciamento de imóveis rurais, observa-se que as maiores discrepâncias encontradas nesse estudo foram da ordem de $0,42 \mathrm{~m}$, o que possibilita a discussões a respeito da aplicação de ortofotos geradas a partir de sensores acoplados em uma plataforma VANT para fins de tal atividade, como por exemplo, georreferenciamento de áreas menores que quatro módulos fiscais, que compete ao INCRA a execução e custeio do levantamento. Além disso, como mencionam Dale e Mc Laughlin (1990), apud Loch (1992), as informações confiáveis reduzem ou eliminam as incertezas e ajudam a resolver a análise de conflitos ou litígios de terras.

Outro fator relevante refere-se ao CAR, que não tem uma tolerância especificada. Assim, a existência de normas, tolerâncias e especificações técnicas seria de suma importância para uma melhor gestão e utilização do CAR, tornando-se indispensável para sua integração ao CTM, buscando assim construir uma base espacial precisa e ao mesmo tempo confiável.

\section{Conclusão}

No presente trabalho buscou-se avaliar o potencial e a viabilidade na utilização de ortofoto geradas a partir de imagens obtidas por sensores acoplados à plataforma VANT para fins de cadastro, analisando puramente a qualidade posicional e geométrica de tais produtos.

Com a avaliação da acurácia posicional da ortofoto, utilizando métodos de feições lineares e pontuais, obteve-se discrepâncias médias similares, da ordem de $20 \mathrm{~cm}$, sendo o produto acurado posicionalmente para a escala 1:1000, em ambos os métodos. Assim, tal produto pode ser utilizado para fins de gestão de serviços rurais tais como: CAR, áreas de assentamento, agricultura familiar, regularização e planejamento ambiental, zoneamento ecológico econômico, identificação de comunidades rurais, georreferenciamento de imóveis rurais etc.

A possibilidade de aplicação da ortofoto, de forma a auxiliar no georreferenciamento foi fundamentada na análise da Norma Técnica para Georreferenciamento de Imóveis Rurais (NTGIR, 2013), em sua terceira edição, atreladas ao manual técnico de posicionamento e ao manual técnico de limites e confrontantes, disponibilizados pelo INCRA. Tais documentos apresentam a possibilidade de uso de novos métodos de posicionamento para obtenção de limites naturais e inacessíveis através de imagens de sensoriamento remoto.

Nesse contexto, comparando os resultados apresentados para o produto avaliado com valores de precisão posicional estabelecidos por NTGIR (2013), referentes aos vértices definidores dos limites $(0,50 \mathrm{~m}$ ou superiores para os limites artificiais; de 3 metros ou superior para os limites naturais e por fim, de 7,5 m ou superior para os limites considerados inacessíveis), observou-se que é possível se realizar o georreferenciamento de um imóvel rural através de uma ortofoto gerada a partir de imagens obtidas por uma câmera embarcada em um VANT, mostrando-se viável, principalmente, para identificação/demarcação de limites naturais e limites de difícil acesso. 
No entanto, embora atenda os $0,50 \mathrm{~m}$ requeridos pela Norma Técnica de Georreferenciamento, vale ressaltar que o problema de visibilidade dos limites compõe uma limitação a aplicação desse procedimento à este tipo de aplicação. Sendo assim, ainda é necessário que se discuta mais sobre a aplicação de ortofoto adquirida a partir de imagens obtidas por sensores embarcados em VANT ao georreferenciamento de imóveis rurais.

No que concerne ao Cadastro Ambiental Rural, pode-se afirmar que a utilização de ortofoto oriundas de Sistemas Conjuntos (sensores embarcados em VANT) servem como instrumento interessante para a tomada de decisão, à medida que fornece informações com clareza (alta resolução espacial/temporal) e qualidade cartográfica.

Por fim, a partir dos resultados obtidos pela avaliação da qualidade da ortofoto gerada por câmeras de pequeno formato a bordo de um VANT, foi possível sinalizar que há de se discutir, de forma ampla, sobre as possibilidades de utilização/aplicação desse tipo de dado em diversas temáticas, tais como: descrição geométrica de parcelas, reurbanização de favelas, projetos cadastrais em geral para atualização de bairros, assentamento e projetos de reforma agrária, dentre outros.

Em face aos resultados alcançados, recomenda-se para trabalhos futuros avaliar a qualidade posicional planimétrica de produtos obtidos por levantamento aerofotogramétrico, utilizando sensores embarcados em plataformas VANT (ortofotos), variando a quantidades e a configuração de pontos de apoio distribuídos em campo. Propõe-se também, verificar a influência das precisões dos pontos de controle, através de propagação das variâncias, na qualidade da ortofoto.

\section{REFERÊNCIAS BIBLIOGRÁFICAS}

Bento, Maria de Fátima. "Unmanned Aerial Vehicles: An Overview.” In Inside GNSS 54 (2008): 54-61.

BRASIL. "Decreto No 89.817 de 20 de Junho de 1984". Normas Técnicas Da Cartografia Nacional. $\quad$ Brasil, $1984 . \quad$ Acesso 10, setembro, 2015 , http://www.planalto.gov.br/ccivil_03/decreto/1980-1989/D89817.htm.

Braz, Adalto M., Borges, Josué Pedro S., Bernardes, Deany Cristina S., e Terezan, Luiz Henrique. "Análise da aplicação de VANT na atualização de cadastro florestal com uso de pontos de controle." In XVII Simpósio Brasileiro de Sensoriamento Remoto - SBSR, João PessoaPB, Brasil, INPE, 6381-88, 2015.

Castejon, Emiliano F., Fonseca, Leila Maria G., e Arcanjo, Jeferson S. "Melhoria da geometria e posicionamento de imagens orbitais de média resolução: Um experimento com dados CBERSCCD.” In XVI Simpósio Brasileiro de Sensoriamento Remoto - SBSR, Foz do Iguaçu-PR, Brasil, INPE, 8043-8045, 2013.

Chen, Shen-Em, Rice, Corey, Boyle, Chuck, Hauser, Edd, and Philbrick, Brian. "Small-format aerial photography for highway-bridge monitoring." Journal of Performance of Constructed Facilities 25.2 (2011): 105-112.

Dale, P.F., and Mclaughlin, J.D. Land information management, an introduction with special reference to cadastral problems in third world countries. Oxford (USA): Oxford University Press, 1990. 
DSG - Diretoria do Serviço Geográfico. "Especificação Técnica Para a Aquisição de Dados Geoespaciais Vetoriais (ET-ADGV)", Brasil, 2011. Acesso 27, fevereiro, 2015, http://www.geoportal.eb.mil.br/images/PDF/ET_ADGV_Vs_2_1_3.pdf

DSG - Diretoria do Serviço Geográfico. "Especificação Técnica para a Estruturação de Dados Geoespaciais Vetoriais de Defesa da Força Terrestre (ET-EDGV)”, Brasília, Brasil 2015.

Eisenbeiss, Henri. "A mini unmanned aerial vehicle (UAV): system overview and image acquisition." In International Workshop on Processing and visualization using high resolution Imagery, Thailand, Pitsanulok, Novembro, 18-20, 2004.

Ferreira, Alexandre M.R. "Avaliação de câmara de pequeno formato transportada por Veículo Aéreo não Tripulado - VANT, para uso em aerolevantamentos." Dissertação de Mestrado, Instituto de Geociências da Universidade de Brasília, 2014.

FGDC. Geospatial Positioning Accuracy Standards Part 3: National Standard for Spatial Data Accuracy. 1998. Accessed November 10, 2014. http://www.fgdc.gov/standards/projects/FGDCstandards-projects/accuracy/part3/chapter3.

Roig, Henrique L., Ferreira, Alexandre M.R., Menezes, Paulo Henrique B.J., e Marota Giuliano S. "Uso de câmeras de baixo custo acopladas a veículos aéreos leves no estudo do aporte de sedimentos no Lago Paranoá." In XVI Simpósio Brasileiro de Sensoriamento Remoto - SBSR, Foz do Iguaçu-PR, Brasil, INPE, 9308-9315, 2013.

Galo, Mauricio, e Camargo, Paulo Oliveira. "O uso do GPS no controle de qualidade de cartas." In 1 Congresso Brasileiro de Cadastro Técnico Multifinalitário - COBRAC, Florianópolis-SC, Brasil, Vol. 2., p. 41-48, 1994.

Goodchild, Michael F. "Foreword." In Principles of Modeling Uncertainties in Spatial Data and Spatial Analyses. CRC Press. 2010.

Haarbrinck, R.B., and Koers, E. "Helicopter UAV for photogrammetry and rapid response." In Second International Workshop: The Future of Remote Sensing, Antuérpia, Belgium, october, 17-18, 2006.

Karnaukhova, Eugenia, e Loch, Carlos. "Alguns problemas atuais do mapeamento digital." In XX Congresso Brasileiro de Cartografia, Porto Alegre-RS, Brasil, 2001.

Laliberte, Andrea S., Herrick, Jeffrey E., Rango, Albert, and Winters, Craig. "Acquisition, orthorectification, and object-based classification of unmanned aerial vehicle (UAV) imagery for rangeland monitoring." Photogrammetric Engineering \& Remote Sensing Vol. 76, No. 6, June, 661-672, 2010.

Lima, Erly C. "O Levantamento pioneiro da SARA Brasil: histórico, tecnologia empregada e avaliação dos produtos." Dissertação de Mestrado, Escola Politécnica da Universidade de São Paulo, 2012.

Loch, R. E. N. Cartografia: representação, comunicação e visualização de dados espaciais. Florianopolis: Ed. da UFSC, 2006.

Lucieer, Arko, Robinson, S., Turner, D., Harwin, S., and Kelcey, J. "Using a Micro-UAV for ultra-high resolution multi-sensor observations of Antarctic moss beds". In International Archives of the Photogrammetry, Remote Sensing and Spatial Information Sciences - XXII ISPRS Congress, Melbourne, Australia, Volume XXXIX-B1, 2012.

Lunardi, Omar Antônio, Penha, Alex L.T., e Cerqueira, Rodrigo W. "O Exército Brasileiro e os Padrões de Dados Geoespaciais para a INDE ." In IV Simpósio Brasileiro de Ciências Geodésicas e Tecnologias da Geoinformação, Recife, Brazil, 1-8, 2012. 
Marenchino, D. "Low-cost UAV for the Environmental Emergency Management" In Photogrammetric Procedures for Rapid Mapping Activities, Torino, Politecnico di Torino, 2009.

Mesas-Carrascosa, Francisco-Javier, Torres-Sánchez, J., Clavero-Rumbao, I., García-Ferrer A., Peña, J., Borra-Serrano, I., and López-Granados, F. "Assessing Optimal Flight Parameters for Generating Accurate Multispectral Orthomosaicks by UAV to Support Site-Specific Crop Management." Remote Sensing 7-10 (2015): 12793. Accessed October 20, 2015, doi:10.3390/rs71012793.

Nebiker, S., Annena, A., Scherrerb, M., and Oesch, D. "A Light-Weight Multispectral Sensor for micro UAV - Opportunities for very high resolution airborne remote sensing." In The International Archives of the Photogrammetry, Remote Sensing and Spatial Information Sciences - XXI ISPRS Congress. Beijing, China, July 3-11, 2008.

Nex, Francesco, and Remondino, F. "UAV for 3D mapping applications: a review." Applied Geomatics 6. (2014): 1-15. Accessed November 10, 2014. doi:10.1007/s 12518-013-0120-x.

NTGIR, Instituto Nacional de Colonização e Reforma Agrária. Norma Técnica para Georreferenciamento de Imóveis Rurais. Brasília, 2013. $3^{\text {a }}$ Edição.

Pegoraro, Antoninho João, e Philips, J.W. "Quadrirotores/Microdrone como Portadores de Geosensores aplicados ao Cadastro Territorial”. In XV Simpósio Brasileiro de Sensoriamento Remoto - SBSR, Curituba-PR, Brasil, INPE, 8461-8468, 2011.

Roberto, Arcádio J. "Extração de Informação Geográfica a partir de Fotografias Áéreas obtidas com Vants para apoio de SIG Municipal”. Dissertação de Mestrado, Faculdade de Ciências da Universidade do Porto, 2013.

R Core Team. "R: A Language and Environment for Statistical Computing." R Foundation for Statistical Computing, 2014.

Santos, Afonso Paula. "Avaliação da Acurácia Posicional em sados espaciais com o uso de Estatística Espacial." Dissertação de Mestrado, Departamento de Engenharia Civil da Universidade Federal de Viçosa, 2010.

Santos, Afonso Paula, Medeiros, Nilcelene das Graças, Rodrigues, Dalto D. "Controle de qualidade posicional em dados espaciais utilizando feições lineares," Boletim de Ciências Geodésicas, v. 21, nº 2, p. 233-250, abr-jun, 2015.

Sztutman, Paulo. "Análise da qualidade posicional das bases do Google Maps, Bing Maps e da Esri para referência espacial em projetos em SIG: aplicação para o município de São Paulo". Tese de Doutorado, Universidade de São Paulo, 2014.

Tong, Xiaohua, Sun, T., Fan, J., Goodchild, M.F. and Shi, W. "A Statistical Simulation Model for Positional Error of Line Features in Geographic Information Systems (GIS)." International Journal of Applied Earth Observation and Geoinformation 21 (2013): 136-48. Accessed October 10, 2015. doi:http://dx.doi.org/10.1016/j.jag.2012.08.004.

Tveite, Havard, and Langaas, Sindre. "An Accuracy Assessment Method for Geographical Line Data Sets Based on Buffering." International Journal of Geographical Information Science 1 (1999): 27-47. Accessed October 5, 2015. doi:10.1080/136588199241445.

Recebido em 30 de dezembro de 2015.

Aceito em 01 de maio de 2016. 